\title{
EFEITOS DA ADIÇÃO DO RESÍDUO DE CORTE DE MÁRMORE E GRANITO (RCMG) NAS PROPRIEDADES DAS ARGAMASSAS DE CIMENTO PORTLAND E INDUSTRIALIZADA NO ESTADO
} APLICADO

\author{
Elenice Carmo de Abreu Apolinário
}

\section{Gabriel Ricardo Silva Santos}

\section{Daniel Véras Ribeiro}

RESUMO: A construção civil é o principal consumidor de recursos naturais do planeta. Assim, o desenvolvimento de materiais que utilizam matérias-primas alternativas, tais como o resíduo proveniente do corte de mármore granito (RCMG) pode resultar em soluções satisfatórias do ponto de vista técnico-econômico e ambiental. Neste sentido, o RCMG, gerado pelas indústrias de processamento de rochas ornamentais para a utilização na construção civil, foi devidamente caracterizado e adicionado às argamassas simples (cimento Portland e areia) e às argamassas industrializadas, nos teores de $0 \%$ (referência), 1,4\%, 2,8\% e 4,2\% em relação à massa total de materiais secos. A seguir, analisaram-se as propriedades no estado aplicado: dureza superficial (NBR 7584/1995), resistência de aderência à tração (NBR 13528/2010) e absorção de água sob-baixa pressão ao longo do tempo, (método 11.4 - RILEM). A adição do RCMG às argamassas mostrou-se satisfatória, atingindo-se os melhores resultados quando adicionado um teor de $2,8 \%$ e $1,4 \%$ às argamassas simples e às argamassas industrializadas, respectivamente. 
Palavras chave: Argamassa. Resíduo de mármore e granito. Filler.

\section{INTRODUÇÃO}

Nos dias atuais, a sustentabilidade ganha mais força e atinge todos os setores, pois a transformação é imprescindível. As mudanças estão ocorrendo e são visíveis em todas as áreas profissionais e não é diferente no setor da construção civil, que tem crescido muito nos últimos anos, pois, são nas áreas urbanas que se concentram os maiores aglomerados populacionais e, por conseguinte, as maiores extrações de recursos naturais, sendo a construção civil um dos setores que mais impacta o ambiente, responsável por consumir $75 \%$ desses recursos no planeta (FECOMÉRCIO, 2012). No Brasil, cerca de 210 milhões de toneladas de agregados naturais são empregados anualmente na produção de concretos e argamassas (JOHN, 2000). Essa enorme demanda tem esgotado as reservas de matérias primas próximas aos grandes centros urbanos, gerando maior consumo de energia, poluição e ônus para os produtores no transporte desses materiais a longas distâncias.

Alternativas que viabilizem o reaproveitamento de resíduos da construção civil, assim como a redução do seu volume, melhorias no manejo, transporte, armazenamento e destinação final, pensando em todo o ciclo de vida dos materiais, serão triviais nos próximos anos. Em muitos setores, o volume de resíduo gerado durante a produção pode ser muito alto. No caso das rochas ornamentais, 20 a 30\% dos blocos serrados nas pedreiras transformam-se em resíduo de corte de mármore e granito, (ALYAMAÇ, 2009; HAGGAR, 2009; GONÇALVES, 2000).

Segundo a ABIROCHAS (2013), em 2008, a produção mundial de rochas foi cerca de 105 milhões de toneladas e o Brasil foi responsável por 7,8 milhões, sendo que $63 \%$ da produção nacional foram destinadas aos mármores, travertinos, granitos e similares, o equivalente a cinco milhões de toneladas. Fazendo uma estimativa entre a produção e a quantidade de resíduo gerada durante o processo, chega-se ao montante 


\section{. \\ Fórum Ambiental}

da Alta Paulista

ISSN 1980-0827
Volume 9, Número 1, 2013

Aplicação de Novas

Tecnologias Sustentáveis

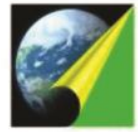

ANAP

de, aproximadamente, 1,25 milhões de toneladas de resíduos de corte de mármore e granito.

O ciclo produtivo de rochas ornamentais compreende três etapas básicas: a extração das rochas nas pedreiras, medindo em torno de $3,0 \times 2,0 \times 1,5 \mathrm{~m}$, o beneficiamento primário, constituído pela serragem dos blocos através dos teares, em grandes chapas de aproximadamente $2,80 \times 1,90 \times 0,02 \mathrm{~m}$ e por fim, o beneficiamento secundário ou acabamento final, quando as chapas são enviadas às marmorarias para que sejam realizados os cortes em partes menores e os polimentos conforme o pedido do cliente (RODRIGUES et al, 2011; SETEC/MEC, 2007).

Durante o beneficiamento primário, além do resíduo do corte, granalha, cal e água formam uma lama abrasiva com grande potencial para argamassas e concretos, pois possui grande estabilidade e resistência à abrasão (APOLINÁRIO et al, 2012). A aplicação do resíduo em matrizes cimentíceas tem se mostrado uma alternativa viável, (GONÇALVES, 2000; MENEZES et al, 2009; ARUNTAŞ et al 2010; CORINALDESI et al, 2010; TOPÇU et al, 2009), pela elevada finura e pela utilização como filler, minimizando o uso de recursos naturais, contribuindo para suprir as necessidades habitacionais, reduzindo custos, respeitando a geodiversidade e, consequentemente, a biodiversidade. Durante o beneficiamento primário, muitas vezes o resíduo é depositado a céu aberto, sem nenhum tratamento prévio, causando sérios danos ao meio ambiente.

Com o intuito de melhorar este cenário, o presente estudo consistiu em analisar o efeito da adição de RCMG nos teores de 1,4\%, 2,8\% e 4,2\% em relação à massa de materiais secos e avaliar as propriedades das argamassas simples (cimento e areia) e industrializadas aplicadas em painéis de alvenaria compostos por blocos cerâmicos.

\section{MATERIAIS E MÉTODOS}

\subsection{Materiais}


Para confecção das argamassas simples foi utilizado cimento CP-II Z 32 RS da marca Poty, areia natural quartzosa, água proveniente da rede pública de abastecimento da Empresa Baiana de Água e Saneamento S.A. (Embasa) e resíduo de corte de mármore e granito (RCMG). Para a mistura das argamassas industrializadas, foi apenas acrescentado o RCMG, sendo essas fornecidas pelo próprio fabricante, da marca Contimassa, de múltiplo uso e bombeável, destinadas a revestir paredes e tetos. As proporções dos seus componentes não foram reveladas, porém ela é composta por cimento, areia, cal e aditivos (incorporador de ar e plastificante).

Com relação aos teores de resíduo adicionados às argamassas, inicialmente, 0 estudo foi realizado com a adição de RCMG nas argamassas simples, nos teores de 5\%, $10 \%$ e $15 \%$ em relação à massa de cimento. No entanto, como a quantidade de cimento existente nas argamassas industrializadas não foi disponibilizada pelo fabricante, optouse por fazer a adição de RCMG com relação à massa total de materiais secos. Portanto, para manter os mesmos teores de 5\%,10\% e 15\% de adição em relação à massa de cimento nas argamassas simples, fez-se uma equivalência para a massa total de materiais secos, resultando então, para ambas as argamassas, em uma adição de 1,4\%, $2,8 \%$ e $4,2 \%$ de RCMG em relação à massa de materiais secos.

O RCMG coletado na forma de lama foi gerado por uma marmoraria localizada na Região Metropolitana de Salvador, durante o beneficiamento secundário das rochas. Assim, possui composição química diversificada, formada por proporções indefinidas de mármore e granito, a depender dos tipos de rochas comercializados pela empresa. Portanto, o lote em estudo pode apresentar variações em relação a outras pesquisas.

\subsection{Métodos}

\subsubsection{Caracterização das Matérias-Primas}

A análise granulométrica da areia, a distribuição do tamanho de partículas e o módulo de finura foram realizados através de peneiramento manual conforme a NBR 7211/2009 ("Agregados para concreto - Especificação"), a massa específica foi determinada pelo método do frasco de Chapman e a massa unitária pelo procedimento da 
NBR NM 45/2006 ("Agregados - Determinação da massa unitária e do volume de vazios").

As caracterizações físicas do cimento CP II Z 32 RS e do RCMG foram realizadas pelo Laboratório de Formulação e Síntese Cerâmica da Universidade Federal de São Carlos (LAFSCer - UFSCar). Determinou-se a massa específica (Helium Pycnometer Accupyc 1330 V2.01 da Micrometrics), a área superficial BET (Micrometrics Gemini 2370 V1.02) e a distribuição do tamanho de partículas por meio de um sedígrafo (Horiba CAPA700). A caracterização mineralógica foi realizada por difração de raios-X (Rigaku Geirgeflex ME 210GF2 Diffractometer) do Instituto de Física da Universidade de São Paulo (IFUSP) e a composição química, por fluorescência de raios-X (Philips PW1480 X ray Fluorescence Spectrometer), realizada pelo SGS GEOSOL Laboratórios Ltda.

\subsubsection{Preparo das Argamassas e Construção dos Painéis}

A partir de estudos disponíveis na literatura e dos experimentos realizados, definiu-se o traço da argamassa simples de referência sendo 1,00:2,60:0,59 (cimento : areia : água), sobre o qual adicionou-se a quantidade de RCMG igual a 1,4\%, 2,8\% e $4,2 \%$ em relação à massa seca. A relação água/cimento foi mantida constante, como parâmetro de controle, e não foram empregados aditivos, com o intuito de observar o comportamento da argamassa contendo RCMG, sem qualquer tipo de influência.

A quantidade de água adicionada à mistura das argamassas industrializadas foi determinada mediante as recomendações indicadas pelo fabricante, (no máximo 16,8\% em relação à massa seca) e pelo índice de consistência fixado em $260 \mathrm{~mm} \pm 10 \mathrm{~mm}$ (flow table), pois, como nas argamassas simples, a relação água/materiais secos (a/ms) se manteve constante para todos os teores de adição. Assim, o traço de referência da argamassa industrializada foi de 1,00: 0,171 (argamassa industrializada : água), sobre 0 qual adicionou-se o RCMG nos teores de 1,4\%, 2,8\% e 4,2\% em relação à massa seca. $A$ mistura das argamassas foi realizada em betoneira, por 17 minutos ( $\pm 1 \mathrm{~min}$ ).

Para a avaliação do revestimento aplicado foram construídos oito painéis de blocos cerâmicos, com aproximadamente $1,00 \mathrm{~m}$ de largura $\times 1,50 \mathrm{~m}$ de altura. $\mathrm{O}$ traço da 
argamassa utilizada para o assentamento dos blocos e para o chapisco foi de 1:3 (cimento: areia). Os painéis foram construídos em área externa coberta a fim de se reproduzir condições climáticas reais para a realização dos ensaios. Após $24 \mathrm{~h}$ da construção dos painéis, foi aplicado chapisco tradicional com três milímetros de espessura, composto por cimento, areia e água, conforme NBR 7200/98. Sobre o chapisco foi aplicada a argamassa em camada única, totalizando uma espessura de aproximadamente $2,5 \mathrm{~cm}$ conforme a NBR 13749/96. A cura dos painéis foi realizada a seco para ilustrar as piores condições (UNGERICHT \& PIOVESAN, 2011), visto que, em muitos casos, não se realiza a cura adequada em revestimentos externos.

\subsubsection{Análise de Desempenho}

a) Avaliação da dureza superficial pelo esclerômetro de reflexão (NBR 7584/1995)

Para este ensaio, adaptou-se a NBR 7584/95, tradicionalmente utilizada para concreto endurecido, a fim de ser utilizada para argamassas. Após 28 dias de cura, a avaliação do ensaio consiste em um método não destrutivo que mede a dureza superficial da argamassa, visando fornecer elementos de avaliação de integridade, resistência e qualidade da argamassa endurecida por meio de esclerômetro de reflexão. O índice esclerométrico representa o valor, em porcentagem, da energia recuperada pelo esclerômetro, após o impacto.

\section{b) Resistência de aderência à tração (NBR 13528/2010)}

A aderência do revestimento sobre os painéis de alvenaria foi avaliada aos 28 dias. Foram distribuídos 12 pontos de análise, de forma aleatória, em cada painel (referência, 1,4\%, 2,8\% e 4,2\%). A resistência de aderência à tração (Ra), em $\mathrm{MPa}$, originou-se da relação entre a força de ruptura $(F)$, em Newton, e a área de aplicação da carga $(A)$ em $\mathrm{mm}^{2}$. Assim, formas de ruptura apresentadas pelos corpos de prova foram indicadas, em porcentagem, conforme o grau de ocorrência, classificando-se em: (a) interface substrato/chapisco (b) interface chapisco/argamassa, (c) interior ou superfície da argamassa e (d) substrato. 
c) Absorção de água sob-baixa pressão. (método, RILEM 11.4 - Réunion Internationale dês Laboratoires d'Essais et de Recherches sur les Matériaux et lês Constructions, 1982)

Para a obtenção do índice de absorção de água sob-baixa pressão por um determinado tempo foi utilizada a pipeta de Karsten (RILEM - 11.4), popularmente conhecida pelo método do cachimbo. Este método consiste em analisar a quantidade de água absorvida pelos painéis, por um tempo, através de tubos graduados em forma de cachimbo, fixados nas paredes. Na medida em que a água permeia pela parede é possível analisar o grau de absorção e determinar a qualidade da argamassa.

\section{RESULTADOS E DISCUSSÃo}

\subsection{Caracterização das Matérias-Primas}

Os resultados da caracterização física do cimento CP || Z 32 RS (Tabela 1), mostram que o diâmetro médio de suas partículas (D50), fica em torno de $0,05 \mathrm{~mm}$ $(50 \mu \mathrm{m})$, mostrando-se um material pulverulento.

Tabela 1: Análise física do cimento CP II Z 32 RS

\begin{tabular}{cc}
\hline Características & Resultados \\
\hline Diâmetro médio de partículas (D50) & $0,05 \mathrm{~mm}$ \\
\hline Área superficial espećfica BET & $1,09 \mathrm{~m}^{2} / \mathrm{g}$ \\
\hline Massa específica & $3,25 \mathrm{~kg} / \mathrm{dm}^{3}$ \\
\hline
\end{tabular}

A composição química do cimento (Tabela 2) está de acordo com a NBR11578/1997 ("Cimento Portland composto - Especificação") que fixa os teores máximos para alguns compostos, como: o trióxido de enxofre $\left(\mathrm{SO}_{3}\right)$, com o máximo de $4,0 \%$, por ser um composto instável, corrosivo e por reagir violentamente com a água, o óxido de magnésio ( $\mathrm{MgO}$ ), com até $6,5 \%$, pois, ao se hidratar em água, transforma-se lentamente em hidróxido de magnésio $\left[\mathrm{Mg}(\mathrm{OH})_{2}\right]$, gerando expansão de volume e tensões internas suficientes para provocar trincas e fissuras em argamassas e concretos 
(RODRIGUES \& FONSECA, 2009) e a perda ao fogo (PF) a $1000^{\circ} \mathrm{C}$, que deve ser no máximo de $6,5 \%$, para suportar altas temperaturas em casos de incêndio.

Tabela 2: Composição química do cimento CP II Z 32 RS

\begin{tabular}{c|c|c|c|c|c|c|c|c|c|c}
\hline \multicolumn{10}{c}{ Composição química (\%) } \\
\hline $\mathrm{SiO}_{2}$ & $\mathrm{Al}_{2} \mathrm{O}_{3}$ & $\mathrm{Fe}_{2} \mathrm{O}_{3}$ & $\mathrm{CaO}$ & $\mathbf{M g O}$ & $\mathbf{S O}_{3}$ & $\mathrm{Na}_{\mathbf{2}} \mathrm{O}$ & $\mathrm{K}_{\mathbf{2}} \mathrm{O}$ & $\mathrm{MnO}$ & $\mathrm{PF}$ & TOTAL \\
\hline 24,50 & 6,10 & 2,50 & 56,00 & 4,00 & 1,80 & 0,50 & 0,30 & 0,07 & 4,10 & 100,00 \\
\hline
\end{tabular}

*PF: Perda ao fogo a $1000^{\circ} \mathrm{C}$

A caracterização física do RCMG é apresentada na Tabela 3. Observa-se que o tamanho do diâmetro médio das partículas (D50) ficou em torno de 0,012mm (12 $\mu \mathrm{m}$ ), mostrando que este é consideravelmente mais fino que o cimento e, consequentemente, possui maior área superficial específica BET. Esses indicativos mostram a propensão do resíduo em preencher os espaços vazios da mistura, atuando como filler.

Tabela 3 Caracterização física do RCMG

\begin{tabular}{cc}
\hline Características & Resultados \\
\hline Diâmetro médio de partículas (D50) & $0,012 \mathrm{~mm}$ \\
\hline Área superficial específica BET & $3,540 \mathrm{~m}^{2} / \mathrm{g}$ \\
\hline Massa específica & $2,920 \mathrm{~kg} / \mathrm{dm}^{3}$ \\
\hline
\end{tabular}

Através da análise química do RCMG (Tabela 4) é possível observar a predominância de sílica $\left(\mathrm{SiO}_{2}\right)$, cerca de $37,6 \%$, contribuindo para uma característica de composto inerte. Apesar de o RCMG conter $8,21 \%$ de óxido de magnésio ( $\mathrm{MgO}$ ) e esta quantidade ser superior à permitida pela NBR11578/1997, para fabricação dos cimentos, o conteúdo de 4,2\% de RCMG, adicionado à argamassa simples, não prejudica a mistura. Pois, a soma da quantidade de MgO presente no RCMG e da quantidade de $\mathrm{MgO}$ presente no cimento (proporcional ao traço com $4,2 \%$ de adição de resíduo) resultam em 5,23\% de MgO, não ultrapassando 6,5\%, o permitido pela NBR11578/1997. 
O óxido de cálcio ou cal livre $(\mathrm{CaO})$ foi o composto com a segunda maior concentração presente no RCMG, aproximadamente 17,7\%. Esse óxido, ao se hidratar durante o endurecimento das argamassas, aumenta de volume e cria tensões internas que conduzem à microfissuração, podendo desencadear a desagregação das argamassas (BAUER, 2005). Observam-se, ainda, teores de alumina $\left(\mathrm{Al}_{2} \mathrm{O}_{3}\right)$ e de óxido férrico $\left(\mathrm{Fe}_{2} \mathrm{O}_{3}\right)$, proveniente das lâminas de corte, iguais a $9,04 \%$ e $4,89 \%$, respectivamente.

Tabela 4 Composição química do Resíduo de Corte de Mármore e Granito (RCMG)

\begin{tabular}{c|c|c|c|c|c|c|c|c|c|c|c}
\hline \multicolumn{10}{c}{ Composição química (\%) } \\
\hline $\mathrm{SiO}_{2}$ & $\mathrm{Al}_{2} \mathrm{O}_{3}$ & $\mathrm{Fe}_{2} \mathrm{O}_{3}$ & $\mathrm{CaO}$ & $\mathbf{M g O}$ & $\mathrm{TiO}_{2}$ & $\mathbf{P}_{2} \mathrm{O}_{5}$ & $\mathbf{N a}_{2} \mathrm{O}$ & $\mathbf{K}_{2} \mathrm{O}$ & $\mathbf{M n O}$ & $\mathbf{P F}$ & TOTAL \\
\hline 37,6 & 9,04 & 4,89 & 17,7 & 8,21 & 0,78 & 0,33 & 1,79 & 2,5 & 0,07 & 17,29 & 100,00 \\
\hline
\end{tabular}

${ }^{*} \mathrm{PF}$ : Perda ao fogo a $1000^{\circ} \mathrm{C}$

As fases que compõem o RCMG podem ser observadas no difratograma da Figura 1, onde há a presença de minerais existentes no granito, como quartzo $\left(\mathrm{SiO}_{2}\right)$, aluminossilicatos de cálcio $\left(\mathrm{CaAl}_{2} \mathrm{Si}_{2} \mathrm{O}_{8}\right)$ e flogopita, da família das micas, classe dos filossilicatos, de fórmula química $\mathrm{KMg}_{3}\left(\mathrm{Si}_{3} \mathrm{Al}\right) \mathrm{O}_{10}(\mathrm{OH})_{2}$ e de minerais presentes no mármore, como a dolomita, $\mathrm{CaMg}\left(\mathrm{CO}_{3}\right)_{2}$. É importante salientar que não ocorreu a formação de MgO periclásio, responsável por expandir e gerar fissuras em argamassas e concretos (NEVILLE, 1997).

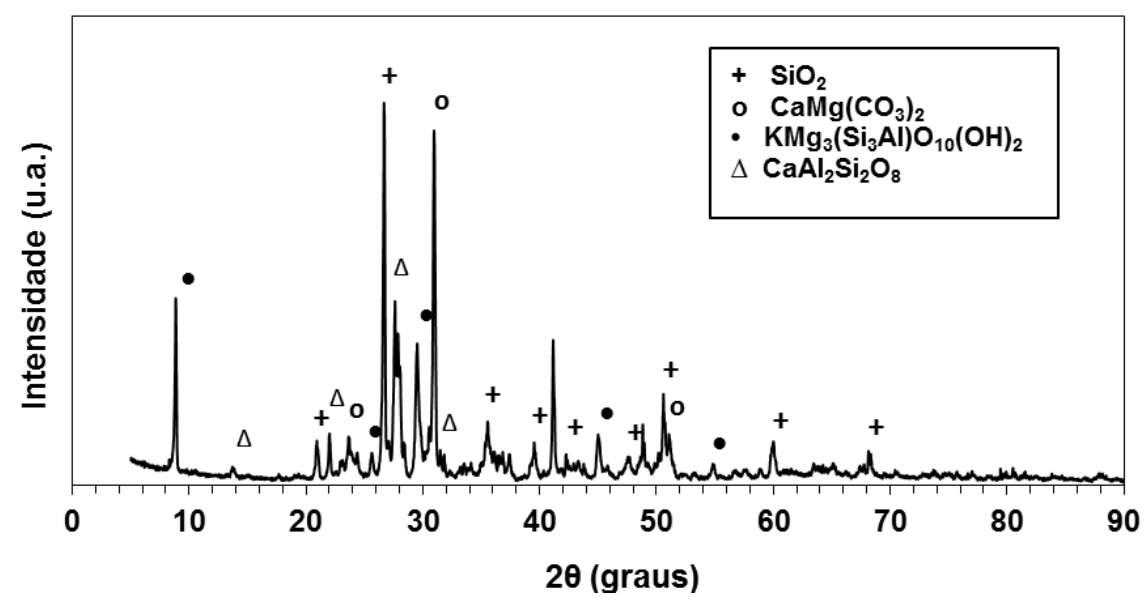

Figura 1: Difratograma de raios $\mathrm{X}$ do $\mathrm{RCMG}$ 
A caracterização física da areia pode ser observada pela Tabela 5, onde esta possui elevada finura e é considerada "muito fina" pela NBR 7211/1983 e de acordo com a NBR 7211/2009, está situada dentro do limite utilizável inferior.

Tabela 5: Caracterização física da areia

\begin{tabular}{cc}
\hline Características & Resultados \\
\hline Diâmetro médio de partículas (D50) & $0,30 \mathrm{~mm}$ \\
\hline Massa específica & $2,62 \mathrm{~kg} / \mathrm{dm}^{3}$ \\
\hline Massa unitária & $1,59 \mathrm{~kg} / \mathrm{dm}^{3}$ \\
\hline Módulo de finura & $1,70 \mathrm{~kg} / \mathrm{dm}^{3}$ \\
\hline Dimensão máx. característica & $2,36 \mathrm{~mm}$ \\
\hline
\end{tabular}

A distribuição granulométrica pode ser observada pela Figura 2:

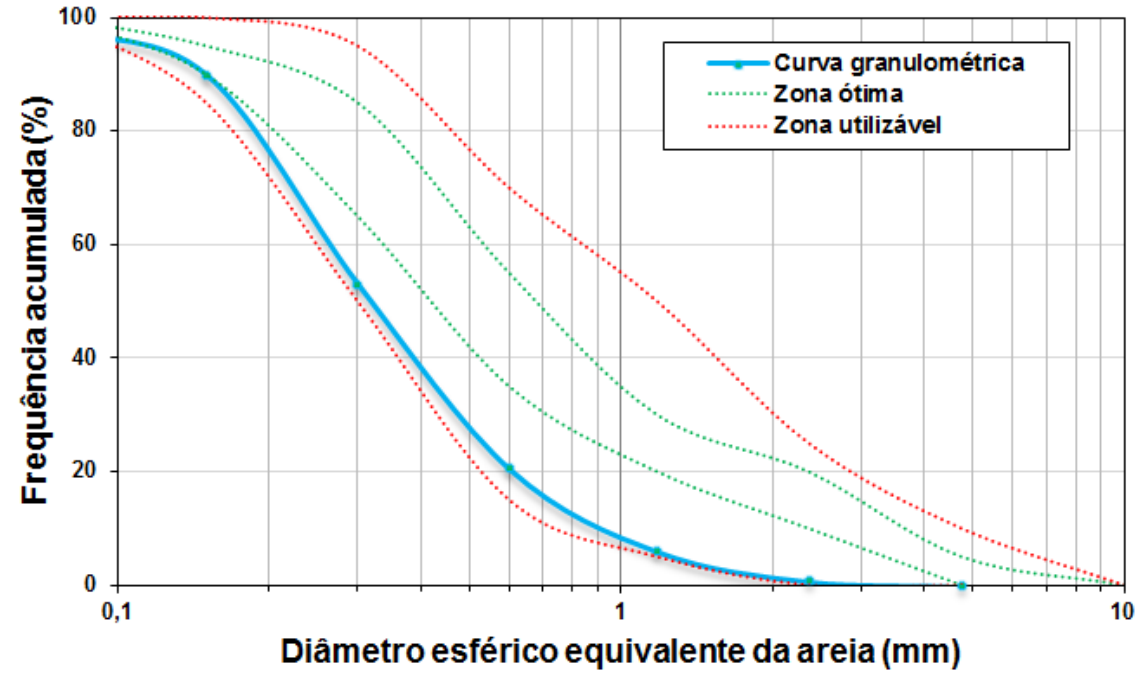

Figura 2: Distribuição granulométrica da areia.

O comparativo entre a granulometria do resíduo, do cimento e da areia é apresentado na Figura 3, sendo o diâmetro médio de partículas (D50) do RCMG, do cimento e da areia, respectivamente, iguais a $0,012 \mathrm{~mm}, 0,050 \mathrm{~mm}$ e $0,300 \mathrm{~mm}$. 


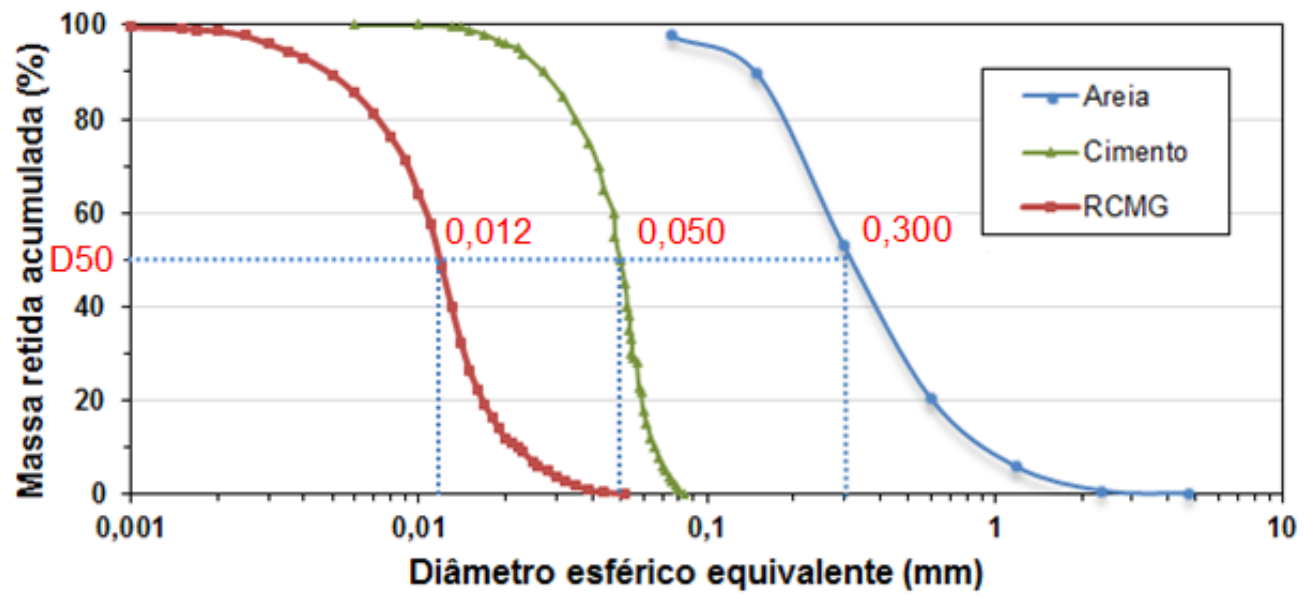

Figura 3: Distribuição granulométrica do RCMG, do cimento e da areia.

\subsection{Análise de Desempenho das Argamassas no Estado Aplicado}

3.2.1 Avaliação da dureza superficial pelo esclerômetro de reflexão (NBR 7584/1995)

Os resultados de dureza superficial dos painéis, aos 28 dias, podem ser observados na Figura 4. O índice esclerométrico mede, indiretamente, a densidade/homogeneidade da argamassa aplicada e, consequentemente, a sua dureza. Assim, a argamassa mais homogênea apresenta maior índice esclerométrico. Com a adição de 2,8\% de RCMG à argamassa simples, houve um aumento de $14,6 \%$ na dureza superficial do painel, pois, devido a sua alta finura, o resíduo preenche a estrutura dos poros, contribui para densificar a zona de transição e melhorar as propriedades mecânicas das argamassas nas idades iniciais (GONÇALVES, 2000). No entanto, com adições superiores a 2,8\%, as partículas finas de RCMG fazem com que haja absorção excessiva de água de mistura, dificultando o empacotamento e prejudicando a reologia das argamassas (CASTRO \& PANDOLFELLI, 2009), a aplicação ao painel e, consequentemente, sua homogeneidade. 


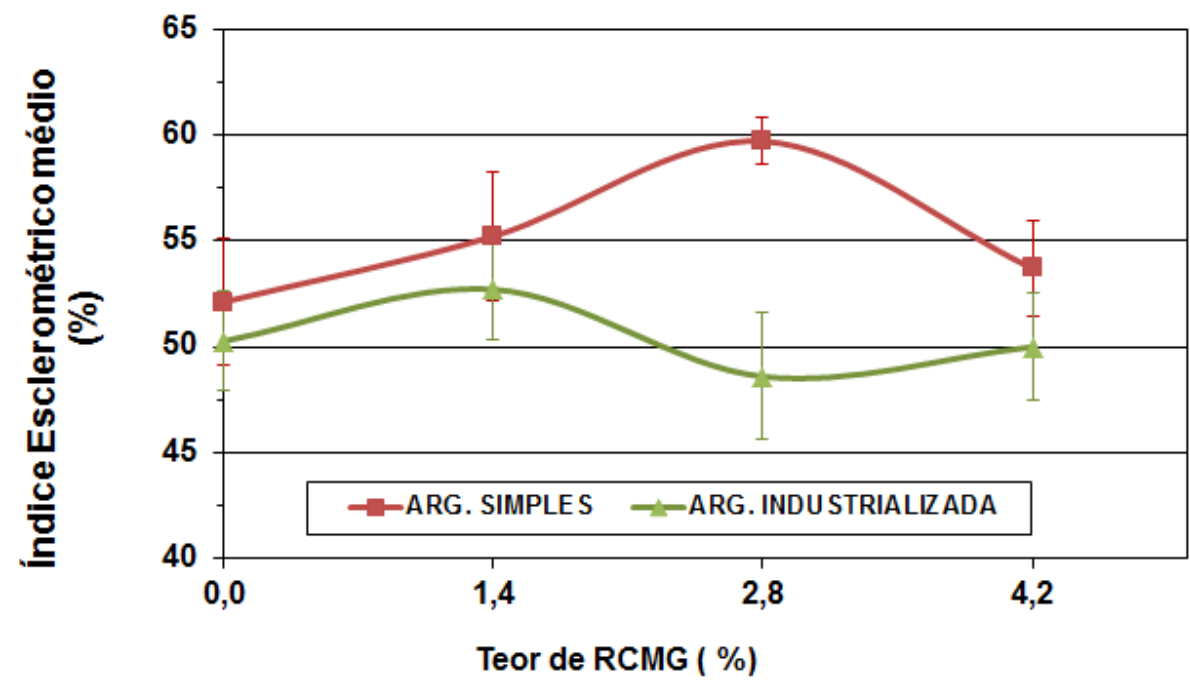

Figura 4: Índice esclerométrico médio (IE) em função dos teores de RCMG

\subsubsection{Resistência de aderência à tração (NBR 13528/2010)}

Conforme observado na Figura 5, a resistência de aderência à tração (NBR 13528/2010) das argamassas simples com adição de RCMG apresentou resultados superiores se comparados à argamassa de referência, porém, as argamassas industrializadas apresentaram um comportamento inverso. No entanto, todos os resultados estão conforme a NBR13749/1996 ("Revestimento de paredes e tetos de argamassas inorgânicas - Especificação"), que preconiza a resistência mínima das argamassas para revestimentos externos em 0,30 MPa. Observa-se que nas argamassas simples, os valores de resistência de aderência à tração foram elevados em função do aumento de teor de RCMG, em aproximadamente $36 \%$, para os teores de $2,8 \%$ e $4,2 \%$ de adição de RCMG em relação à argamassa de referência. A diminuição da resistência de aderência à tração nas argamassas industrializadas é devido à adição de aditivo incorporador de ar, pois, as bolhas de ar reduzem a superfície de contato na interface argamassa/substrato, dificultando a aderência das argamassas (CARASEK, 2001). Resultados semelhantes foram encontrados por Carasek (2001) e Silva et al (2009). 


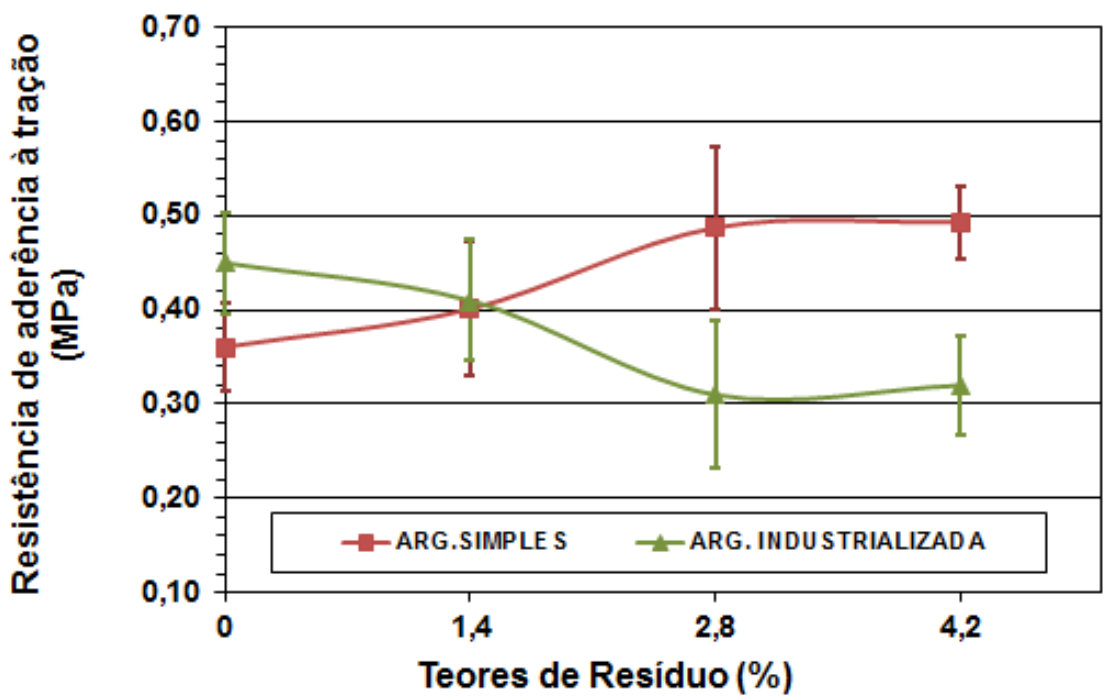

Figura 5: Resistência de aderência à tração em função dos teores de RCMG.

Os resultados das incidências das formas de ruptura apresentadas pelos corpos de prova após o arrancamento das argamassas simples e industrializadas estão apresentados na Figura $6 \mathrm{~A}$ e $6 \mathrm{~B}$, respectivamente. Quanto mais profundo for 0 arrancamento, melhor homogeneidade possui a argamassa, sendo assim, a melhor condição de ruptura ocorre no substrato, tipo (d), seguido da ruptura do tipo (a) - interface chapisco/substrato, depois a ruptura do tipo (b) - interface argamassa chapisco e por fim, as piores condições de rupturas acontecem no interior das argamassas, tipo (c), indicando que essas não estão coesas. Na Figura 6(A), as argamassas simples com o acréscimo de $2,8 \%$ e $4,2 \%$ de RCMG, apresentaram maior coesão na mistura devido ao aumento da proporção de finos e melhor empacotamento das partículas, pois a forma de ruptura no interior da argamassa deixou de existir em ambos os casos. O teor de 2,8\% de RCMG apresentou resultados mais equilibrados, demonstrando melhor coesão e homogeneidade na mistura, pois, obteve um aumento da ruptura do tipo (d), seguido do tipo (b) e do tipo (a). 
0\% referência - SIMPLES

$5 \% \quad 2 \%$

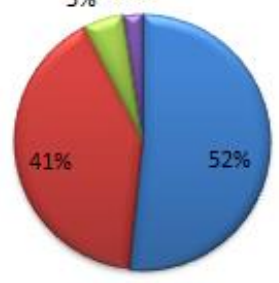

(a) Interface chapisco / substrato

(A)

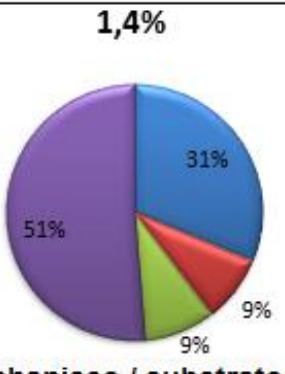

(b) Interface argamassa/ chapisco
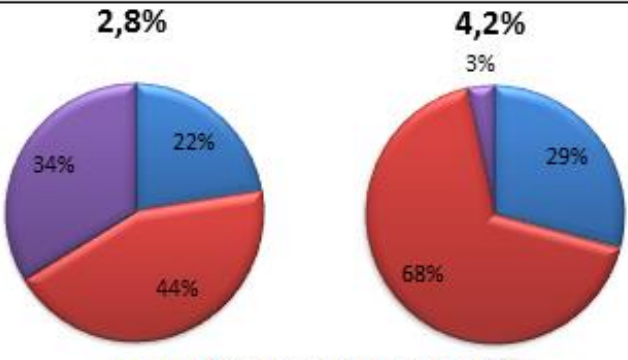

(c) Interior da argamassa

(d) Substrato

Figura 6(A): Incidência das formas de ruptura observadas após o ensaio de resistência de aderência à tração em função dos teores de RCMG adicionados nas argamassas simples

No caso das argamassas industrializadas, em geral, a ruptura do tipo (b), na interface argamassa/ chapisco, prevaleceu para todas as situações. No entanto, mesmo ocorrendo rupturas do tipo (c) no interior das argamassas contendo o RCMG, observa-se melhora na coesão da mistura devido ao aumento da ruptura do tipo (a) na interface chapisco/substrato e na redução do tipo (d), no substrato.

\begin{tabular}{|l|l|l|}
\hline O\% referência - IND & $\mathbf{1 , 4 \%}, \mathbf{2 , 8} \%$ \\
(B) \\
(a) Interface chapisco / substrato \\
(b) Interface argamassa/ chapisco \\
(c) Interior da argamassa
\end{tabular}

Figura 6(B): Incidência das formas de ruptura observadas após o ensaio de resistência de aderência à tração em função dos teores de RCMG adicionados nas argamassas industrializadas.

3.2.3 Absorção de água sob-baixa pressão. (método 11.4, RILEM - Réunion Internationale dês Laboratoires d'Essais et de Recherches sur les Matériaux et lês Constructions, 1982)

A Figura 7 apresenta os resultados do coeficiente de absorção de água realizados pelas argamassas simples e industrializada. 


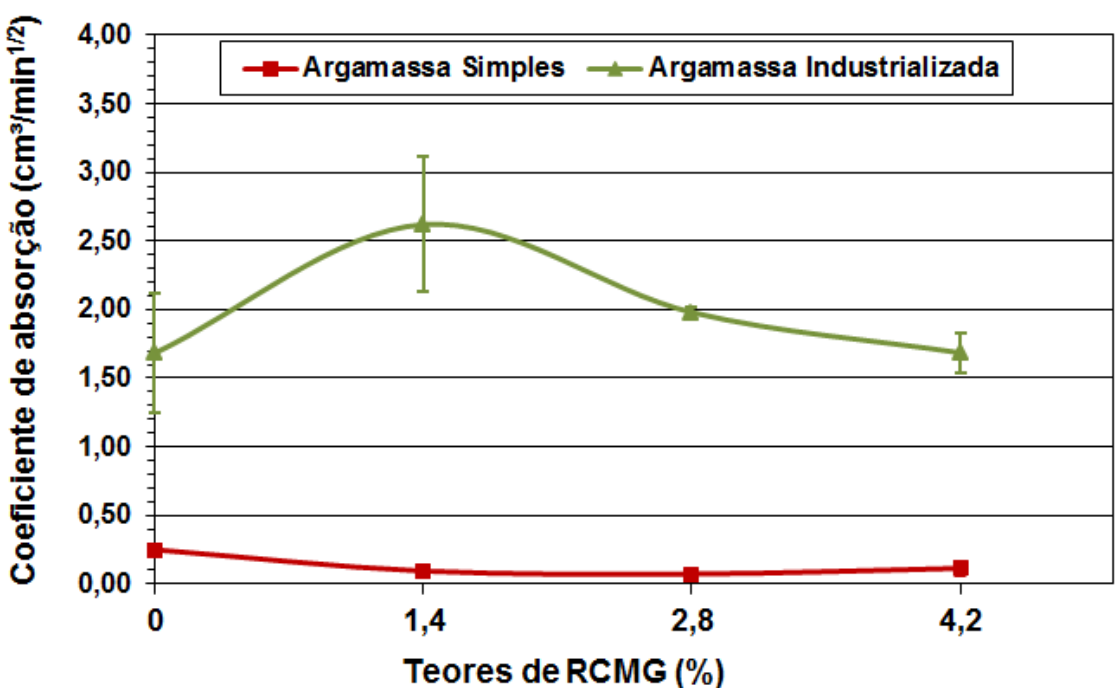

Figura 7. Coeficiente de absorção das argamassas simples e industrializada em função dos teores de RCMG.

Observa-se que as argamassas simples contendo RCMG tiveram ligeira queda na absorção de água com relação à argamassa de referência, evidenciando a melhora nas condições da mistura e na distribuição granulométrica dos agregados, pois os grãos finos do RCMG preenchem os poros e, consequentemente, evitam a absorção de água. Em contrapartida, houve maior absorção de água nas argamassas industrializadas, pois quanto maior a absorção, maior a quantidade de poros e, consequentemente, menor a resistência de aderência à tração. Nos estudos realizados por Lawrence \& Cao (1988) apud Carasek (2001), observou-se que a microestrutura da argamassa aditivada com 0 substrato não é contínua e possui grande quantidade de vazios, refletindo em maior absorção de água.

\section{CONCLUSÕES}

O RCMG age como filler, preenchendo os espaços vazios, favorecendo a nucleação heterogênea, ativando a hidratação do cimento e catalisando o processo de nucleação dos hidratos por meio da redução da barreira de energia, por isso melhorou a qualidade das argamassas simples em todos os ensaios. 
O RCMG por ter alta finura, possui maior área superficial, preenchendo os poros capilares e consequentemente, reduzindo a permeabilidade e aumentando a aderência e a resistência das argamassas simples.

As argamassas industrializadas possuem resultados inferiores às argamassas simples devido ao aditivo incorporador de ar atuar aumentando a quantidade de vazios, reduzindo a superfície de contato entre a argamassa e o substrato, resultando na diminuição da resistência de aderência à tração e maior absorção de água.

Com base nos resultados, os melhores teores de adição do RCMG foram aproximadamente 2,8\% para as argamassas simples e 1,4\% para as argamassas industrializadas. Quantidades superiores de RCMG podem prejudicar a reologia e, consequentemente, as propriedades e durabilidade em ambas as argamassas.

\section{AGRADECIMENTOS}

Agradecimentos ao Mestrado de Engenharia Ambiental Urbana da Universidade Federal da Bahia (MEAU/UFBA), ao Laboratório de Ensaios em Durabilidade dos Materiais (LEDMA), ao Centro Tecnológico da Argamassa (CETA) e ao técnico Paulo César de Jesus Sant'anna (DCTM/CETA/UFBA).

\section{REFERÊNCIAS}

ABNT - NBR 11578 : 1997 - Cimento Portland composto - Especificação

NBR 13276:2005 - Argamassa para assentamento e revestimento de paredes e tetos - Preparo da mistura e determinação do índice de consistência

NBR 13528: 2010 - Revestimento de paredes e tetos de argamassas inorgânicasDeterminação da resistência de aderência à tração.

NBR 13749: 1996 - Revestimento de paredes e tetos de argamassas inorgânicas

NBR 7200/1998 - Execução de revestimento de paredes e tetos de argamassas inorgânicas - Procedimento. 
ISSN 1980-0827
Volume 9, Número 1, 2013

Aplicação de Novas Tecnologias Sustentáveis

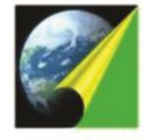

ANAP

NBR 7211: 2009 - Agregados para concreto - Especificação

NBR 7584: 1995 - Concreto endurecido - Avaliação da dureza superficial pelo esclerômetro de reflexão.

\section{vazios}

NBR NM 45/2006 - Agregados - Determinação da massa unitária e do volume de

ALYAMAÇ, K. E.; INCE, R.; A preliminary concrete mix design for SCC with marble powders. Construction and Building Materials, v 23, p.1201-2010, 2009.

ALVES, N. J. D. Avaliação dos aditivos incorporadores de ar em argamassas de revestimento. Dissertação (Mestrado em Estruturas e Construção Civil) - Departamento de Engenharia Civil e Ambiental, Universidade de Brasília, Brasília, 2002, 175p.

APOLINÁRIO E.C.A., MATTA, V.R.P.; RIBEIRO, D.V. Efeito da adição do resíduo de corte de mármore e granito (RCMG) nas propriedades das argamassas de revestimento, CEBECIMAT, 2012.

ARUNTAŞ, H.; GÜRÜ, M.; DAYI. M.; TEKIN, I. Utilization of waste marble dust as an additive in cement production. Materials and Design, v.31,p.4039-4042, 2010.

ASSOCIAÇÃO BRASILEIRA DA INDÚSTRIA DE ROCHAS ORNAMENTAIS. (ABIROCHAS). Situação mundial e posição brasileira no setor de rochas ornamentais em 2008. Disponível em: <http://www.ivolution.com.br/news/ upload_pdf/6661/Situacao_Mundial2008.pdf>. Acesso em mar. 2013.

BAUER, E. (Ed.). Revestimentos de argamassa: características e peculiaridades. Brasília: LEM-UnB/Sinduscon-DF, 2005.

CARASEK, H; CASCUDO, O.; SCARTEZINI, L.M. Importância dos materiais na aderência dos revestimentos de argamassa. In: IV Simpósio Brasileiro de Tecnologia das Argamassas ( IV SBTA). Brasilia, 2001

CASTRO, A. L., PANDOLFELLI V. C. Revisão: Conceitos de dispersão e empacotamento de partículas para a produção de concretos especiais aplicados na construção civil. Cerâmica v.55, p.18-32, 2009

CORINALDESI, V.; MORICONI, G.; NAIK, T. R. Characterization of marble powder for its use in mortar and concrete. Construction and Building Materials, v. 24, p. 113-117, 2010.

FEDERAÇÃO DO COMÉRCIO DE BENS, SERVIÇOS E TURISMO DE SÃO PAULO (FECOMERCIO). Sustentabilidade não é só sobre desmatamento e emissão de poluentes. Disponível em:<http://www.fecomercio.com.br/?option=comeventos\&view= interna\&ltemid=20\&id=3363> Acesso em jul 2012. 
ISSN 1980-0827
Volume 9, Número 1, 2013

Aplicação de Novas Tecnologias Sustentáveis

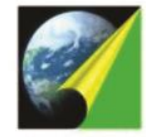

ANAP

GONÇALVES, J. P. Utilização do resíduo de corte de granito (RCG) como adição para a produção de concretos. Porto Alegre, 2000. 135f. Dissertação (Mestrado) em Engenharia Civil, Universidade Federal do Rio Grande do Sul.

HAGGAR, Salad M. El. Sustainable Industrial Design and Waste Management: Cradle-to-cradle for Sustainable Development. p..346-350, 2009.

JOHN, V. M. Reciclagem de resíduos na construção civil: Contribuição para metodologia de pesquisa e desenvolvimento. São Paulo, 2000.113p. Tese (Livre Docência) - Escola Politécnica da Universidade de São Paulo, Departamento de Engenharia de Construção Civil.

MENEZES, R. R.; FARIAS FILHO, J.; FERREIRA, H. S.; NEVES, G. A., FERREIRA, H. C. Reciclagem de resíduos da construção civil para a produção de argamassas. Cerâmica, v. 55 , p. $263-270,2009$.

NEVILLE, Adam M., Propriedades do concreto. $2^{\circ}$ ed. São Paulo: Pini, 1997. 828p.

RILEM. - Réunion Internationale dês Laboratoires d'Essais et de Recherches sur les Matériaux et lês Constructions, Método 11.4, France, 1982.

RODRIGUES, A. F. S.; FONSECA, D. S. Cimento. In: Economia Mineral do Brasil. Brasília: Departamento Nacional de Produção Mineral (DNPM), 2009. p. 636-654.

RODRIGUES, G. F.; ALVES, J. O.; TENÓRIO, J. A. S.; ESPINOSA, D. C. R. Estudo de resíduos de rochas ornamentais para a produção de materiais vítreos. Tecnologia em Metalurgia e Materiais. São Paulo, v. 8, p. 203-207, 2011.

SECRETARIA DE EDUCAÇÃO PROFISSIONAL E TECNOLÓGICA (SETEC)/ MINISTÉRIO DA EDUCAÇÃO (MEC). Rochas Ornamentais. Brasília, 2007.

SILVA, N.G.; COLLODETTI, G.; PICHETTI, D.Z.C.M.; GLEIZE, P.J.P. Efeitos do ar incorporado nas propriedades do estado endurecido em argamassas de cimento e areia. Anais. IBRACON, 2009

TOPÇU, I.; BILIR, T.; UYGUNOĞLU, T. Effect of waste marble dust content as filler on properties of self-compacting concrete. Construction and Building Materials, v 23, p.1947-1953, 2009.

UNGERICHT , A.J. PIOVESAN, A.Z. Influência da cura da argamassa em relação às propriedades mecânicas e absorção de água. Unoesc \& Ciência - ACSA, Joaçaba, v. 2, n. 1, p. 75-86, 2011. 